\title{
Licensing the market for technology
}

\author{
Ashish Arora ${ }^{a}$, Andrea Fosfuri ${ }^{b, c, *}$ \\ ${ }^{a}$ Carnegie Mellon University, Pittsburgh, PA, USA \\ ${ }^{\mathrm{b}}$ Department of Business, Universidad Carlos III de Madrid, Calle Madrid 126, 28903 Getafe, Madrid, Spain \\ ${ }^{\mathrm{c}}$ CEPR, London, UK
}

\begin{abstract}
In technology-based industries, incumbent firm often license their technology to potential competitors. Such a strategy is difficul to explain within traditional models of licensing. This paper extends the literature on licensing by relaxing the assumption of a monopolist technology holder. Competition in the market for technology induces licensing of innovations and incumbent firm may fin it privately profitabl to license although their joint profit may well be higher in the absence of any licensing. A strong testable implication of our model is that the number of licenses per patent holder decreases with the degree of product differentiation.
\end{abstract}

JEL classificatio D23; D43; L13

Keywords Licensing; Market structure; Product differentiation

\section{Introduction}

The importance of licensing as a means for generating revenues from innovations is increasing in a number of technology-intensive industries. Degnan (1998) find that in 1996 , US corporations received US\$ 66 billion in royalty income from unaffiliate entities. A recent study by Anand and Khanna (2000) on strategic alliances reports that licensing is common in sectors such as chemicals, biotechnology, software, computers, and electrical and non-electrical machinery, accounting for about 20-33 percent of all alliances, depending on the sector.

In some industries, it is fairly common to observe large established companies consciously adopting a strategy of licensing for generating revenues. For instance, in chemicals, Union

\footnotetext{
* Corresponding author. Tel.: +34-91-6249351; fax: +34-91-6249607.

E-mail address fosfuri@emp.uc3m.es (A. Fosfuri).
} 
Carbide and Montecatini have actively licensed their polyethylene and polypropylene technology (Grindley and Nickerson, 1996). In the computer industry, IBM patent licensing revenues reached $\$ 1$ billion in 1998, accounting for over 10 percent of IBM's net profit (Rivette and Kline, 1999). In semiconductors, Texas Instruments is reported to have earned royalties of over US\$ 1.8 billion between 1986 and 1993, a figur comparable to Texas Instruments' cumulative net income during this period (Grindley and Teece, 1997). ${ }^{1}$ The noteworthy feature is that often these firm license their technology to other firm that could potentially compete with them.

This constitutes something of a challenge to the traditional wisdom that holds that an innovator can best profi from the innovation by commercializing it himself (e.g. Teece, 1986). In this view, licensing is undesirable because the innovator has to share some of the rents with the licensee, because there are considerable transaction costs in writing contracts upon technological knowledge and especially because licensing increases competition, and hence, dissipates rents.

Traditional explanations for licensing build on the idea that firm license if they are less able (or unable) to exploit the innovation than the potential licensees, or they attempt to establish their technology as a de facto standard, for instance when network externalities are important. ${ }^{2}$ Both of these motivations are well known and accordingly we ignore them here.

In this paper, we develop a model where the interaction between a market for technology, where firm sell their technology through licensing, and a product market, where firm sell their output, generates new insights for understanding firms licensing decisions. The key to our argument is that competition in the product market creates a strategic incentive to license. Specificall, licensing imposes a negative pecuniary externality upon other incumbents in the product market, which the licensor ignores. ${ }^{3}$ Put differently, licensing reduces industry profit because of increased competition but increases a licensor's share of such profits As a result, if there are two or more incumbent firm that have proprietary technologies that are substitutes for each other, both firm may fin it privately profitabl to license, although their joint profit may well be higher in the absence of any licensing. ${ }^{4}$

Our results are driven by two main effects that licensing generates on the profit of the licensor. The first the revenue effect, is given by the rents earned by the licensee which will accrue to the patent holder in the form of licensing payments. The second, the rent dissipation effect, is given by the erosion of profit that the licensor experiences in his own business

\footnotetext{
${ }^{1}$ In the cases of IBM and Texas Instruments, part of these revenues might be due to patent enforcement actions rather than to a deliberate strategic choice about whether and how much to license. However, Rivette and Kline report that both firm have undertaken a policy of actively licensing some of their technologies.

2 The economic literature has analyzed several strategic motivations for licensing, most notably licensing as a mechanism to deter entry, enhance demand or control prices, which we shall briefl review below.

${ }^{3}$ Critical to the argument is competition in the product market. In our model, only firm with access to the technology can produce. In principle, however, one can think of fringe firm that compete in the product market but do not have proprietary technology to license. We briefl discuss this case in Section 2.1 but our main focus in this paper is on competition between technology holders.

4 The presence of competing technologies is not a mere theoretical possibility. The chemical industry is a rich source of examples. As reported in Arora (1997), Union Carbide, Himont and Mobil compete with each other in selling polypropylene licenses; BP and Du Pont compete in polyethylene process technology; UOP, Mobil-BP and Phillips Petroleum in methyl tert-butyl ethers (MTBE).
} 
due to an additional competitor in the product market. Notice that the rent dissipation effect, although similar in spirit, does not coincide with what the industrial organization literature has identifie as efficienc effect (see Tirole, 1988). The efficienc effect captures the negative relationship between aggregate industry profit and the number of producers. Whereas the efficien y effect is measured at the industry level, the rent dissipation effect is measure at the fir level. Since we are interested in studying firms incentives to license, the latter is the relevant level of analysis.

If there is only one incumbent in the product market, the rent dissipation effect dominates the revenue effect whenever industry profit are maximized by monopoly (i.e. the efficienc effect holds, as is typically the case). ${ }^{5}$ Instead, when another incumbent exists the losses due to increased competition are shared with the other incumbent in the product market so that the licensor does not fully internalize the reduction in industry profits When the revenue effect is larger than the rent dissipation effect, then firm compete not only to supply the products but also to supply their technologies.

The revenue effect crucially depends on the inefficiencie of licensing contracts. Our results confir that lower transaction costs lead to more licensing. The degree of product differentiation across technologies has an important influenc on the magnitude of the two effects. If the goods are differentiated, the licensee will be a stronger competitor of the technology holder in the product market than of the other producers. This enhances the rent dissipation effect and reduces the profitabilit of the licensing strategy. Thus we fin that licensing will be more widespread as the degree of product differentiation becomes lower. Moreover, one would expect that the rent dissipation effect would depend on the production and commercial capabilities of the licensor. Large, well-established producers have less to gain from licensing and more to lose from competition. Our results confir that, all else held equal, research labs license more. Interestingly enough, the model also yields a less straightforward result, namely that the presence of independent labs may induce producer-innovators to license more as well.

Finally, we show that incumbent firm would benefi from restricting their licensing activity. This suggests that technology holders might have incentives to collude in order to reduce or stop licensing and hence increase profits Interestingly enough, this also implies that factors that stimulate licensing - for instance, stronger patents that might lower transaction costs - potentially hurt rather than benefi technology holders.

The importance of strategic effects in vertically linked markets is not new and has been discussed in many other multistage models of oligopoly (see Tirole). Within this strand, our paper relates closely to the literature on delegation. As Vickers (1985), Bonanno and Vickers (1988), and Hadfiel (1991) among others have argued, delegation allows a fir to commit itself credibly to alter its behavior and thereby elicit favorable reactions from rivals. We apply the insights from this literature to explain why and how much licensing takes place. In our model, licensing is a credible commitment to expand production by transferring the output decision to the licensees.

The mechanism at work is very similar to the one used by the literature on strategic divisionalization to explain the incentives of firm to create divisions. For instance, Corchon

\footnotetext{
5 Although assuming that the efficienc effect holds is a useful benchmark, it is not crucial for the comparative statics we work out in the paper.
} 
(1991) shows that, by delegating output decisions to divisions managers who do not internalize the inframarginal effects of their actions, the fir can virtually act as a Stackelberg leader and therefore collect larger profit (see also Baye et al., 1996). Similarly, Schwartz and Thompson (1986) argue that divisionalization can be used as a commitment to expand production and hence deter entry. The difference in our paper arises from the fact that with licensing contracts, rent extraction is not complete (because of transaction costs), that we allow for product differentiation across technologies and asymmetries across licensors (producers versus research labs), and that we endogenize the number of incumbents.

By contrast, much of the literature on licensing - to which this paper is also strongly related-has focused on the optimal licensing behavior of the monopolist inventor once it has developed and patented a new technology or production process (see Gallini and Wright, 1990; Kamien and Tauman, 1986). Katz and Shapiro (1986) discuss the optimal number of licensees for a single technology holder who does not compete in the product market. Instead, we analyze how the number of licenses sold is affected by competition from other technology holders, by the strength of patent protection, and by the nature of demand. When the innovator is also active in the product market, then either only minor innovations are licensed (Gallini, 1984; Katz and Shapiro, 1985; Rockett, 1990a) or licensing is used strategically to enhance demand (Shepard, 1987), to choose competitors after the patent expires (Rockett, 1990b), or to deter entry (Gallini, 1984). ${ }^{6}$ Hence, one contribution of this paper is to combine two strands of the economic literature, one on vertical-related markets and the other on licensing that have been treated separately till now.

The rest of the paper is organized as follows. Section 2 presents the model and characterizes the conditions under which the equilibrium involves licensing and the effects of the nature of demand, of transaction costs, and of market structure. Section 3 examines the licensing behavior of research labs versus producers. Section 4 shows that, with multiple licensors, increasing the efficien y of licensing contracts can diminish profitabilit and hence the incentives for R\&D. Section 5 extends our analysis to capture the interaction between the market for technology and market for innovation. It shows that, under fairly general conditions, allowing free entry into the market for innovation leaves earlier results qualitatively unchanged. Section 6 brings together our main finding and concludes the paper.

\section{The model}

Consider a sector where $N$ firm have independently developed and patented proprietary technologies for the production of a good. Such a good can either be perfectly homogeneous across technologies or differentiated. When the good is differentiated, each variety is assumed to be an equally imperfect substitute for all the others.

Besides the $N$ patent holders, we assume that there exist many potential entrants who do not have innovative capabilities but can produce if they receive the rights to use the

\footnotetext{
${ }^{6}$ In Shepard's paper, licensing constitutes a credible commitment to a higher quality that, in turn, enhances demand.
} 
technology from one of the incumbents. ${ }^{7}$ We also assume that other than licensing fees, there are no entry costs. Incumbents can therefore both produce a product themselves (by using their installed production facilities) and license their technology to potential entrants. A licensee produces the same variety of the good as the original licensor. ${ }^{8}$

Let $k_{i}-1$ be the number of licenses sold by fir $i=1,2, \ldots, N$. Hence, the total number of firm that have the technology and can produce the (differentiated) good is equal to $\sum_{i=1}^{N} k_{i}$. For analytical tractability we shall consider $k_{i}$ and $N$ to be continuous variables.

We assume that the licensor makes a take-it or leave-it offer to the licensee and extracts all the net surplus generated by the use of the technology through an upfront fi ed fee. In particular, we do not allow for contracts with per-unit royalties. ${ }^{9}$ Instead, we allow for non-exclusive licensing contracts, a common practice in technology licensing (see, for example, Anand and Khanna, 2000).

However, as the large existing literature on technology transfer has emphasized (see, for instance, Teece, 1977), contracting for technology involves transaction costs. These costs include the costs of writing contracts as well as the costs of transferring know-how. Indeed, it is well known that technology licensing can require the transfer of tacit know-how. The tacitness makes it difficul for third parties, such as courts, to monitor the transfer of such know-how. Thus, a buyer of technology must guard against the seller opportunistically under-supplying know-how. Conversely, the seller must guard against the buyer holding up payment for such transfer. Thus, licensing contracts may result in sub-optimal levels of know-how transfer (Taylor and Silberston, 1973; Teece, 1977). We model transaction costs as having a fi ed component, $F$, and a variable component which corresponds to a share $(1-\sigma) \in[0,1]$ of the profit earned by the licensee through the use of the technology. It seems reasonable to assume that the inefficien y due to the sub-optimal levels of know-how transfer would be roughly proportional to the overall value of the contract. In addition, this matches the empirical findin that on average licensors capture only a share of the total rents generated in a licensing contract (Caves et al., 1983). ${ }^{10}$

We analyze the following three-stage game. First, potential innovators have to invest in $\mathrm{R} \& \mathrm{D}$ in order to develop and patent their proprietary technology ("competition in the market for innovation"). Second, each patent holder decides how many licenses to sell to

\footnotetext{
7 This assumption guarantees that licensors do not have to compete for suitable licensees, implying that they can extract all the net surplus generated by the use of their technology. Relaxing this assumption would reduce the revenue effect (i.e. the amount of rents a technology holder can collect through licensing), thereby restricting the parameter space under which licensing occurs at equilibrium. We can partially cover this case through an exogenous increase in transaction costs.

8 Thus, our model is better suited for process licensing rather than product licensing.

9 The design of the optimal license contract, for both exclusive and non-exclusive contracts has been studied by Katz and Shapiro (1986) and Gallini and Wright (1990) among others. Output based royalties are typically used as a response to asymmetric information or moral hazard, or to induce licensees to reduce output. We ignore information problems here. Restricting licensee output is sub-optimal for the licensor because the same outcome can be achieved more efficientl by reducing the number of licensees and saving on transaction costs. Therefore, a lump sum payment contract is the optimal contract in our model.

${ }^{10}$ Notice that, besides transaction costs, there are several other reasons that we do not consider here, for the licensor being unable to extract the full rents generated by its technology, including asymmetric information (Gallini and Wright, 1990), bargaining positions of the parties and the ability of the licensee to invent around the patent once licensing negotiations have begun due to weak intellectual property rights (Gallini, 1992).
} 
potential entrants ("competition in the market for technology"), and third, all firm that have acquired the technology will supply the (differentiated) good ("competition in the product market"). Notice that these three stages correspond to the distinction between 'goods market', 'technology market', and 'innovation market' introduced by the Antitrust Guidelines for the Licensing of Intellectual Property (1995). For much of the paper, we focus on the last two stages of the game, treating $N$ as exogenous. However, in Section 5 we extend our analysis to the whole game showing that all results remain qualitatively unchanged. We proceed by backward induction.

\subsection{Competition in the product market}

We assume Cournot competition in the product market. ${ }^{11}$ Inverse demand function for each variety $i$ has the following linear schedule: ${ }^{12}$

$$
p_{i}=1-\sum_{k_{i}} x_{i}-\mu \sum_{N \backslash i} \sum_{k_{j}} x_{j},
$$

for any $i=1,2, \ldots, N$, where $p_{i}$ denotes the price, the firs summation is across quantities supplied by firm producing $i$, and the second summation is across all quantities supplied by firm endowed with technology different from $i$ ( $N \backslash i$ stands for all varieties but $i$ ).

Here, a key parameter is $\mu$, which captures the degree of product differentiation across varieties. We assume that $\mu \in[0,1]$, with varieties being homogeneous for $\mu=1$ and completely differentiated (independent) for $\mu=0$. To keep things simple, we assume that all technologies allow production at zero marginal cost. Also, notice that we are implicitly imposing that the good is perfectly homogeneous within the group (i.e. all firm using the same technology) and equally differentiated across all groups.

Denote by $\pi^{i}\left(k_{i}, k_{-i}, \mu, N\right)$ the profit accruing to each fir endowed with technology $i$ in the last stage of the game, where $k_{-i}$ stands for the vector $\left\{k_{1}, k_{2}, \ldots, k_{i-1}, k_{i+1}, \ldots, k_{N}\right\}$ of firm endowed with technologies different from $i$. In Appendix A, we show that $\pi^{i}\left(k_{i}, k_{-i}\right.$, $\mu, N)=A^{-2} B^{-2}$ where $A=\left[1+(1-\mu) k_{i}\right]$ and $B=\left[1+\sum_{j}^{N} \mu k_{j} /\left(1+(1-\mu) k_{j}\right)\right]$. Furthermore, $\pi^{i}$ is decreasing and convex in $k_{i}$. Notice that for $\mu=0$ each firm' profi only depends on the number of firm producing that given variety. Instead, for $\mu=1, \pi^{i}$ depends on the total number of firm active in the market $\sum_{i=1}^{N} k_{i}$.

\subsection{Competition in the market for technology}

Given the results of quantity competition in the last stage of the game, one can express each patent holder's profi as a function of the number of firm producing each variety of

\footnotetext{
11 We have also worked out a model with price competition and multinomial logit demand (see Arora and Fosfuri, 1999). Many of the results derived here hold unchanged. Obviously, with price competition, we need to impose some degree of product differentiation also within the same technology. Otherwise, the revenue effect would drop to zero and the strategic incentives for licensing analyzed here would disappear.

12 This demand structure could be derived from the maximization of a quadratic utility function of the form $U\left(X_{1}, \ldots, X_{N}\right)=\sum_{i} X_{i}-(1 / 2) \sum_{i} X_{i}^{2}-\mu \sum_{i} \sum_{j \neq i} X_{i} X_{j}$, where $X_{i}=\sum_{k_{i}} x_{i}$ and $X_{j}=\sum_{k_{j}} x_{j}$ (Singh and Vives, 1984).
} 
the good, $k_{i}$ and $k_{-i}$. That is,

$$
V^{i}\left(k_{i}, k_{-i}, \mu, N, F, \sigma\right)=\left[1+\sigma\left(k_{i}-1\right)\right] \pi^{i}\left(k_{i}, k_{-i}, \mu, N\right)-\left(k_{i}-1\right) F .
$$

Each technology holder $i$ chooses $k_{i}$ in order to maximize its total profi given by the expression above. The first-orde condition is, therefore

$$
V_{k_{i}}^{i}=\sigma \pi^{i}+\left[1+\sigma\left(k_{i}-1\right)\right] \pi_{k_{i}}^{i}-F \leq 0, \quad \text { for } k_{i}-1 \geq 0,
$$

where $\pi_{k_{i}}^{i}$ is the derivative of $\pi^{i}$ with respect to $k_{i}$ given $k_{-i}$.

In Appendix B we show that the second-order condition is satisfie at any interior equilibrium. The first-orde condition (3) shows the two effects discussed in the introduction. The firs one, $\sigma \pi^{i}-F$, corresponds to the revenue effect, the increase in profit from licensing due to an additional licensee. The second, $\left[1+\sigma\left(k_{i}-1\right)\right] \pi_{k_{i}}^{i}$, is negative and corresponds to the rent dissipation effect due to an increase in competition in the product market. The magnitudes of these two effects determine whether firm license at equilibrium, and if so, how many licenses are sold.

Before studying in detail the licensing equilibrium with multiple technology holders, we focus on a simpler case in which a single technology holder faces a fringe of downstream competitors with no access to the licensing strategy. This case nicely illustrates how the presence of other incumbents in the product market affects licensing decisions in the market for technology, independent of the competitive pressure from other technology holders.

\subsection{The case of a single technology holder with competitors in the product market}

We analyze the case where only one firm fir $i$, can license its technology; the remaining $N-1$ firm do not have proprietary technology to license, but are able to produce and compete in the product market. For simplicity and without loss of generality, assume that $\mu=1$. The first-orde condition for fir $i$ can be written as

$$
V_{k_{i}}^{i}=-\frac{\sigma}{\left(k_{i}+N\right)^{3}}\left[k_{i}-1-(N+1)+\frac{2}{\sigma}\right]-F .
$$

It is easy to see that this expression is always negative for any $k_{i} \geq 1$ if $N=1$. However, if $N \geq 2$, this expression can become positive for small values of $F$ and $\sigma$ close to 1 , evaluated at $k_{i}=1$. This result illustrates the key forces behind the licensing decision of the technology holder. When other firm are also able to supply the product $(N>1)$, by licensing fir $i$ expands its market share at the expenses of all other producers. (More precisely, what expands is the market share of producers using technology $i$.) Indeed, with a homogenous good $(\mu=1)$, by licensing, fir $i$ increases its market share from $1 / N$ to $k_{i} /\left(N+k_{i}-1\right)$ while all other producers observe a reduction in their respective market shares from $1 / N$ to $1 /\left(N+k_{i}-1\right)$. However, the presence of additional competitors in the product market results in lower prices. For some range of parameter values, the benefit of an expanded market share outweigh the losses from increased competition and hence fir $i$ chooses to license its technology. Instead, when the innovator is also a monopolist in the product market $(N=1)$, the licensing strategy would not expand fir $i$ 's market share, but it does increase competition in the product market. Thus, a monopolist patent holder would never license. 
Finally, notice that fir i's profit are at least as large with the possibility of licensing as without it and that factors that make licensing more appealing (a reduction in transaction costs) always increase licensor's profits As we shall see later, this is not the case when there are other technology holders that can react by licensing their technology as well.

\subsection{The case of multiple symmetric technology holders}

We now solve the game where $N$ incumbents compete in the market for technology. We focus on the symmetric equilibrium of the second stage of the game and explore how the optimal number of licenses is affected by the parameters of our model. Defin $V_{k}=$ $V_{k_{i}}^{i}\left(k_{i}=k_{-i}=k, \mu, N, F, \sigma\right)=\sigma \pi+[1+\sigma(k-1)] \pi_{k}-F$, where $\pi=\tilde{A}^{-2} \tilde{B}^{-2}$ and $\pi_{k}=$ $-2 \tilde{A}^{-4} \tilde{B}^{-3}[\tilde{A} \tilde{B}(1-\mu)+\mu]$ with $\tilde{A}=[1+(1-\mu) k]$ and $\tilde{B}=1+N \mu k / \tilde{A}$. In other words, $V_{k}$ is the derivative of the payoff function with respect to the number of licenses, evaluated where all technology holders give the same number of licenses. Notice that one could solve explicitly $V_{k}=0$ and fin the symmetric optimal $k$. Unfortunately, the closed-form solution is messy because $V_{k}=0$ is a fourth degree polynomial with two imaginary roots and two real roots. Accordingly, we proceed by using comparative static analysis to examine the effects on equilibrium associated with changes in the parameters. A full characterization of the equilibrium is provided in our working paper (see Arora and Fosfuri, 1999). ${ }^{13}$

Notice that most of the proofs of our propositions greatly simplify for $F=0$. To save space, in what follows we shall often impose this condition and simply conjecture how results would change for positive values of $F$. Complete proofs are in Arora and Fosfuri (1999).

Proposition 1. In a stable symmetric equilibrium, $k$ is increasing in $\sigma$ and decreasing in $F$.

Proof. The key to the proof is that in a stable symmetric equilibrium, the direction of change of $k$ depends only on the sign of the cross-partial of the payoff function. See Appendix D. One can directly verify that $V_{k \sigma} \geq 0$ and $V_{k F} \leq 0$, thus giving us the required results.

Note that Proposition 1 is completely general and does not rely on the assumption of Cournot competition in the downstream market. It implies that any factor that decreases the transaction costs involved in licensing contracts will increase licensing. One of these factors could be stronger patent protection. Indeed, Gallini (1992) argues that stronger patents reduce the ability of the licensee to invent around the patent once licensing negotiations have begun, thereby allowing the licensor to appropriate a larger share of the profit generated by the use of the technology. Arora (1995) formally shows that stronger patents can mitigate the inefficien $y$ in the provision of know-how, as long as patents and know-how are complementary. Complementarity implies that the use of the know-how, which cannot

\footnotetext{
13 In our working paper we show that a symmetric Nash equilibrium, either with no licensing or with positive licensing, generically exists. A symmetric equilibrium does not exist in the limit case in which $F=0$ and $\mu=1$. Reaction functions become parallel straight lines and never cross. In addition, we show that a stable symmetric equilibrium with positive licensing $(k>1)$ is unique and provide necessary conditions for its existence (see Arora and Fosfuri, 1999).
} 
be taken back from the buyer once transferred, is more valuable when used in conjunction with the complementary patents. This allows the licensor to use his patents to protect himself against opportunistic behavior by the licensee. Insofar as stronger patent protection reduces the transaction costs of technology licensing, the results reported by Anand and Khanna provide empirical support for Proposition 1. Based on a sample of 1612 licensing agreements, they fin that sectors where patents are strong are also those with a higher incidence of licensing activity, while sectors with weak patents tend to have joint ventures and other such bundled arrangements for transferring technology. We discuss the effect of patent protection on licensing further in Section 5.

We now examine how the number of competitors, $N$, and the degree of product differentiation in the market, $\mu$, affect licensing.

Proposition 2. For $F=0$, in a stable symmetric licensing equilibrium (SLE), the number of licenses by each technology holder is increasing in $N$.

Proof. At any stable SLE, the direction of change of $k$ depends only on the sign of the cross-partial of the payoff function. By differentiating $V_{k}$ with respect to $N$, one obtains

$$
V_{k N}=\sigma \pi_{N}+[1+\sigma(k-1)] \pi_{k N},
$$

where $\pi_{N}=-2 \mu k \tilde{A}^{-3} \tilde{B}^{-3}$ and $\pi_{k N}=2 \mu k \tilde{A}^{-5} \tilde{B}^{-4}[2 \tilde{A} \tilde{B}(1-\mu)+3 \mu]$.

Using $V_{k}=0$ we can rewrite Eq. (5) as

$$
V_{k N}=\sigma\left(\pi_{N}-\pi \frac{\pi_{k N}}{\pi_{k}}\right)+F \frac{\pi_{k N}}{\pi_{k}} .
$$

It follows that

$$
\pi_{N}-\pi \frac{\pi_{k N}}{\pi_{k}}=\frac{\mu^{2} k \tilde{A}^{-3} \tilde{B}^{-3}}{(1-\mu) \tilde{A} \tilde{B}+\mu},
$$

which is always non-negative. Hence, $V_{k N} \geq 0$ at $F=0$.

From expression (5), one can see that an increase in the number of incumbents involves two forces working in opposite directions. More competition reduces the magnitude of the revenue effect, reducing the payoff from licensing. However, more competition also reduces the size of the rent dissipation effect and hence reduces the opportunity cost of licensing. At $F=0$ the second force prevails. At $F>0$, the two forces have different magnitudes. Nevertheless, one can show that for small values of $N$, increases in competition in the market for technology increase licensing. Only later, as the number of technology holders increases, do further increases in competition decrease licensing by reducing the profitabilit of the product market (see Arora and Fosfuri, 1999 for details).

We now state and prove one of the most robust results of the paper, one that can also be empirically tested most easily, namely that the extent of licensing decreases with the degree of product differentiation. The intuition is quite straightforward. When the good is highly differentiated, each fir has a well-define market niche. Any entrant licensed by the technology holder will be a close competitor to the technology holder himself, 
and the increased competition will be internalized to a greater extent. Instead, when the good is homogeneous, the negative effect due to increased competition is spread across all incumbents while only the licensor shares in the profit of the new entrants. As with the comparative static with respect to $N$, there are two forces at work. On the one hand, less differentiation implies a smaller revenue effect, but on the other hand, it also reduces the rent dissipation effect. It turns out that the second force always prevails. This result holds also for Bertrand competition with multinomial logit demand (see Arora and Fosfuri, 1999).

Proposition 3. At any stable SLE that involves at least one license per technology holder, $k$ is increasing in $\mu$.

Proof. We prove it by contradiction. First, notice that in a stable SLE, the direction of change of $k$ depends only on the sign of the cross-partial of the payoff function. By differentiating $V_{k}$ with respect to $\mu$, one obtains

$$
V_{k \mu}=\sigma \pi_{\mu}+[1+\sigma(k-1)] \pi_{k \mu},
$$

where $\pi_{\mu}=-2 \tilde{A}^{-3} \tilde{B}^{-3} k(N-1)<0$ and $\pi_{k \mu}>0$.

Now, by contradiction, suppose that for some values of $\sigma, V_{k \mu}<0$. Notice that, given $V_{k \mu}<0, V_{k \mu}=\sigma \pi_{\mu}+\sigma k \pi_{k \mu}+(1-\sigma) \pi_{k \mu}>\sigma\left(\pi_{\mu}+k \pi_{k \mu}\right)>\pi_{\mu}+k \pi_{k \mu}>\pi_{\mu}+(k-1) \pi_{k \mu}$. This implies that if $V_{k \mu}<0$, then $\partial V_{k \mu} / \partial \sigma=\pi_{\mu}+(k-1) \pi_{k \mu}<0$. Therefore, if $V_{k \mu}$ is negative for some values of $\sigma, \partial V_{k \mu} / \partial \sigma<0$ implies that $V_{k \mu}$ cannot be positive at $\sigma=1$. However, one can show that, at $\sigma=1$ and $k \geq 2, V_{k \mu}>0$ for all admissible values of $\mu, N$ and $F$, resulting in a contradiction. Hence, $V_{k \mu}$ must be positive at any $k \geq 2$ for all admissible values of $\sigma, \mu, N$ and $F{ }^{14}$

Patterns of technology licensing in the chemical industry provide empirical support for Proposition 3. Elsewhere (see Arora and Fosfuri, 2000) we show that the per-fir number of licenses decreases with the degree of product differentiation in the chemical industry. Homogeneous sectors like air separation, pulp and paper, and petrochemicals are marked by extensive licensing, but we observe only limited licensing by producers in differentiated product groups such as pharmaceuticals and organic chemicals. ${ }^{15}$

\section{Research labs versus large producers}

In this section, we analyze how the presence of firm with limited production capability (i.e. research labs) affects licensing behavior. To simplify our analysis, assume that patent

\footnotetext{
${ }^{14}$ Although positive licensing implies that $k$ should be no less than two, in Arora and Fosfuri (1999) we show that the result reported in Proposition 3 holds at any $k>1$ when either $F=0$, or $N$ is not too large, or product differentiation is low.

15 At this stage, one can wonder whether the socially efficien level of licensing is larger or smaller than the private level of licensing. As long as $N$ is exogenous, it is easy to see that, for zero transaction costs, private licensing is always inefficient Indeed, in this case it is socially optimal to have $k=\infty$. However, with positive transaction costs there can be excessive private licensing. This occurs for large enough values of $N$ because the dead-weight loss of the transaction costs grows accordingly.
} 
holders are of two types - those with manufacturing and marketing capabilities (producers) and those without (research labs). In the latter case, their profi function only depends on the (net) revenues from licensing

$$
V^{r l}=\left(k_{r l}-1\right)\left(\sigma \pi^{r l}-F\right),
$$

where $k_{r l}-1 \geq 0$ is the number of licenses. As one might expect, research labs license more than established producers. The intuition behind this result is fairly simple. Since they have no production capability, the rent dissipation effect is smaller and, hence, licensing is a more appealing strategy. This is stated below:

Result 1. Research labs license more.

Proof. Consider the first-orde condition for a research lab:

$$
V_{k_{r l}}^{r l}=\sigma \pi^{r l}+\sigma\left(k_{r l}-1\right) \pi_{k_{r l}}^{r l}-F=0 .
$$

Now, evaluate this condition at the $k_{i}$ which is optimal for a producer with installed production capabilities. It is easy to see $V_{k_{r l}}^{r l}>0$ giving us the required result.

Perhaps less obvious is how the presence of research labs influence the licensing behavior of firm with installed production facilities.

Proposition 4. At $F=0$, substituting a producer with a research lab increases the average number of licenses given by the remaining producers. ${ }^{16}$

Proof. To show this result it suffice to prove that $V_{k_{i} k_{j}}^{i}>0$, since by Result 1 a research lab always licenses more than a producer. Consider the cross-partial of the profi function in (2) with respect to $k_{i}$ and $k_{j}$, i.e. $V_{k_{i} k_{j}}^{i}=\sigma \pi_{k_{j}}^{i}+\left[1+\sigma\left(k_{i}-1\right)\right] \pi_{k_{i} k_{j}}^{i}$. Using the first-orde condition one obtains

$$
V_{k_{i} k_{j}}^{i}=\sigma\left(\frac{\pi_{k_{j} k_{k_{i}}^{i}}^{i}-\pi^{i} \pi_{k_{i} k_{j}}^{i}}{\pi_{k_{i}}^{i}}\right),
$$

where

$$
\pi_{k_{j}}^{i}=\frac{-2 A^{-2} B^{-3}}{\left[1+(1-\mu) k_{j}\right]^{2}},
$$

and

$$
\pi_{k_{i} k_{j}}^{i}=\frac{2 A^{-4} B^{-4} \mu}{\left[1+(1-\mu) k_{j}\right]^{2}}[2 A B(1-\mu)+3 \mu] .
$$

\footnotetext{
${ }^{16}$ For positive values of $F$, Proposition 4 holds for small values of $N$.
} 
Some additional algebra shows that

$$
V_{k_{i} k_{j}}^{i}=-\frac{2 \sigma A^{-6} B^{-6} \mu}{\pi_{k_{i}}^{i}\left[1+(1-\mu) k_{j}\right]^{2}}>0 .
$$

What this proposition illustrates is an inducement effect. The presence of research labs stimulates the licensing activity of the big firm at a level that it would not have reached otherwise. Elsewhere (see Arora and Fosfuri, 2000) we provide empirical support for this inducement effect. Using data from the chemical industry, we fin that firm without production facilities tend to license more and that in sectors where such firm operate more intensively, large chemical producers themselves tend to license more.

\section{Incentives for $R \& D$}

In Section 2, we have shown that competition in the product market creates a strategic incentive to license. By licensing, firm induce entry and increase product market competition. As well understood in the literature on innovation, an increase in the rate of diffusion also implies a smaller incentive to develop the innovation in the firs place. This is precisely what occurs in our model where a larger $k$ reduces per-fir profits

Proposition 5. With ex-ante symmetric licensors, the possibility of licensing reduces profit per innovator.

Proof. The licensor's profi at any positive symmetric licensing is $[1+\sigma(k-1)]$ $[1+(1-\mu) k+\mu N k]^{-2}-(k-1) F$. Taking the derivative with respect to $k$, it is easy to show that such derivative is always negative. Hence, the licensor's profi is maximized at $k=1$.

Proposition 5 also suggests that technology holders might have incentives to collude in order to reduce or stop licensing and hence increase profits An example of such a practice is provided by the history of the chemical sector. Before WWII, cartels were widespread. The major technology leaders, typically European firms adopted a strict control over their licensing policies in order to keep market shares, deter entry and sustain prices above competitive levels (see Arora, 1997). Such collusion in the market for technology is explicitly analyzed in the Antitrust Guidelines for the Licensing of Intellectual Property (example 2).

Moreover, Proposition 5 underscores the ambiguous effects on the profit of technology holders of factors that increase the efficien y of licensing transactions. Using the envelope theorem, one can show that

$$
V_{\sigma}^{i}=(k-1) \pi^{i}+\sum_{j \neq i} \frac{\partial V^{i}}{\partial k_{j}} \frac{\mathrm{d} k_{j}}{\mathrm{~d} \sigma},
$$

where the second term is negative, and

$$
V_{F}^{i}=-(k-1)+\sum_{j \neq i} \frac{\partial V^{i}}{\partial k_{j}} \frac{\mathrm{d} k_{j}}{\mathrm{~d} F},
$$


where the second term is positive. The effect of $\sigma$ (or $F$ ) on firms profit is ambiguous: on the one hand, a larger $\sigma$ (or a smaller $F$ ) increases licensor's profits on the other hand, it also stimulates (by Proposition 1) the licensing activity of all the other competitors and hence reduces profits In particular, it is readily apparent that if $V_{k}=0$ at $k=1$, then a reduction in the inefficien y of the licensing contracts would actually hurt technology holders by increasing licensing and increasing the total number of firm in the industry. This is stated formally in the following result:

Result 2. At parameter values such that $V_{k}=0$ at $k=1$, an increase in $\sigma$ or a decrease in $F$ reduces profit of each technology holder.

Notice that the relationship between licensor profit and the parameters $\sigma$ and $F$ holds for a larger parameter space than the one given in Result 2. Indeed, through numerical simulations (available from the authors upon request) we have been able to construct several examples that show an increase in $\sigma$ or a decrease in $F$ reduces profit of technology holders. Thus, insofar as stronger patent protection encourages licensing (through higher $\sigma$ or lower $F$ ), it may even lower industry $R \& D$ or reduce the number of firm investing in $R \& D !^{17}$

\section{The 'market for innovation': making $N$ endogenous}

Thus we have so far assumed that the number of incumbents, $N$, is exogenously given. However, it is likely that in order to develop and patent a proprietary technology, firm have to incur substantial costs (for instance, expenditures in R\&D). A forward-looking fir would not commit resources unless future profit are sufficientl large to recover initial investments. Thus, factors affecting the market for technology are also likely to affect the number of potential licensors, in turn will also affect licensing behavior.

This section provides sufficien conditions such that the results presented so far are qualitatively unchanged in a three-stage game where initially firm decide whether to invest in R\&D, and if they do, then they play the game analyzed in Section 2. Specificall, we show that even after modeling the R\&D decision, $k$ is increasing in $\sigma$, decreasing in $F$, and increasing in $\mu$. A sufficien condition for the results to hold is that $\mathrm{d} k / \mathrm{d} N \geq 0$, which is always satisfie for $F=0$.

We assume that there are $\bar{N}$ firm (with $\bar{N}$ sufficientl large) that have the ability to invest in R\&D and develop new technology. The cost of R\&D required to develop a new technology is $G$, which is fi ed. There is no uncertainty, so if a fir pays $G$, it will develop a proprietary technology. Instead, a fir that does not invest $G$ enjoys an outside opportunity that is equal to zero. ${ }^{18}$ We confin our analysis to the case where $G$ is small enough to support at least two firms For larger values of $G$ either only one fir or no fir will invest in R\&D. The following result, that we state for completeness, is quite intuitive.

\footnotetext{
17 This is a simple Prisoner Dilemma situation.

18 Notice that a fir that does not become a technology holder could obtain a license in the second stage of the game, from one of the other innovators. However, given the structure of our game all the rents earned by the licensee are taken away by the licensor through an appropriate upfront fee. So, the outside option is zero.
} 
Result 3. A larger R\&D fi ed cost reduces the number of incumbents, $N$, and the per-fir number of licenses, $k$.

Proof. See Appendix C.

The following two propositions, proved in Appendix C, generalize the results we derived in Section 2 with exogenous $N$.

Proposition 1'. The per-fir number of licenses, $k$, is increasing in $\sigma$ and decreasing in $F$.

Proposition $3^{\prime}$. The more homogenous the products are, the smaller is the number of incumbents, $N$, and the larger is the per-fir number of licenses, $k$.

Proposition $3^{\prime}$ has a strong empirical implication. We should expect that differentiated markets have many technology holders but little licensing activity. Conversely, homogenous markets should be characterized by a smaller number of more active licensors. Notice that we cannot unambiguously predict the effect of changes in $\sigma$ and $F$ on $N$ since, as explained in Section 4, the effect of changes in these two parameters on per-fir profit is a priori ambiguous.

A further qualificatio concerns the effects due to a change in the patent regime. In Section 2, we argued that stronger patents can increase licensing by reducing transaction costs (higher $\sigma$ or lower $F$ ). However, broader patent scope or stronger novelty requirements may also increase $G$ and hence reduce the number of firm that develop proprietary technology.

\section{Conclusion}

There is increasing evidence that firm in some sectors are trying to profi from their intellectual property not just by embodying it in their own output but also by licensing their intellectual property to others, including potential competitors. Such behavior is difficul to understand in the context of models with only a monopolist technology holder, who by definitio faces no competition in the product market. By relaxing the widespread assumption of a monopolist patent holder, our paper shows that licensing might be the result of firms strategic behavior. Indeed, the presence of competition changes the incentives for an incumbent to license its technology to potential entrants. In particular, when there are multiple technology holders, not only do they compete in the product market, but they also compete in the market for technology.

Within this framework, we showed that increases in the efficien y of licensing contracts increase the propensity to license. Although licensing profit increase, the increase in product market competition may reduce overall profit of the innovators. This implies that stronger patents may be a mixed blessing for firm in technology-intensive industries. Although stronger patents raise barriers against imitation by rivals, they may ultimately result in increased product market competition by facilitating licensing. Since licensing partially substitutes for production, firm lacking adequate downstream commercialization 
(production and marketing) capabilities are naturally more aggressive licensors. Interestingly enough, our results indicate that their presence induces more aggressive licensing by their larger rivals with commercialization capabilities as well. Our model provides another important insight - increasing product differentiation not only softens price competition in the product market, but it also reduces the propensity to license in the technology market.

Finally, from an economic policy perspective, the existence of a market for technology implies technology diffusion and increased entry, improving the static efficien y of the market. However, by inducing entry in the product market, a market for technology may reduce the incentives to undertake $R \& D$ and hence restrict entry in the market for innovation.

One limitation of our model is that it does not allow firm to have multiple technologies, something we observe empirically quite frequently. Firms with multiple technologies may have different substitution patterns and, therefore, different patterns of rent dissipation due to licensing. Thus, relaxing the restriction of single technology firm and allowing the model to endogenize the number of technologies made by each fir could be an avenue of future research.

\section{Acknowledgements}

This paper was written while Andrea Fosfuri was visiting the Heinz School of Public Policy and Management, Carnegie Mellon University. The hospitality of the center is gratefully acknowledged. We thank S. Arping, E. Brousseau, B. Cassiman, A. Gambardella, C. Ménard, R. Merges, M. Motta, T. Roende, J. Sandonis, two anonymous referees and participants in seminars at GSIA (Carnegie Mellon University, Pittsburgh), University of Stuttgart, University of Urbino, Jornadas de Economía Industrial (Madrid), University Carlos III (Madrid), University Pompeu Fabra (Barcelona), Sant'Anna School of Advanced Studies (Pisa) and Fondazione Eni Enrico Mattei (Milan) for helpful comments. All errors, of course, remain our own. Financial support from the European Commission through the TSER program, contract SOE1-CT97-1059, and the Spanish Ministry of Science and Technology, grant SEC2000-0395, is gratefully acknowledged.

\section{Appendix A. Deriving the producer's profi function}

Take any fir $i$ (either patent holder or licensees) producing variety $i$. By maximizing fir $i$ 's profit with respect to its own quantity we obtain the following first-orde condition:

$$
1-\sum_{k_{i}} x_{i}-\mu \sum_{N \backslash i} \sum_{k_{j}} x_{j}-x_{i}=0 .
$$

First, impose symmetry across firm using the same technology. Then, by adding and subtracting $\mu \sum_{k_{i}} x_{i}$ we obtain

$$
1-k_{i} x_{i}-\mu \sum_{N} k_{j} x_{j}-x_{i}+\mu k_{i} x_{i}=0
$$


from which

$$
x_{i}=\frac{1-\mu \sum_{N} k_{j} x_{j}}{1+(1-\mu) k_{i}} .
$$

Now, multiply both sides by $\mu k_{i}$ and sum up across all possible varieties to obtain

$$
\sum_{N} \mu k_{j} x_{j}=\left[1-\sum_{N} \mu k_{j} x_{j}\right] \sum_{N} \frac{\mu k_{j}}{1+(1-\mu) k_{j}},
$$

which after some manipulation can be rewritten as

$$
\sum_{N} \mu k_{j} x_{j}=\frac{1}{1+1 /\left(\sum_{N} \mu k_{j} /\left(1+(1-\mu) k_{j}\right)\right)} .
$$

Then, substituting (A.5) in (A.3) and simplifying we obtain the equilibrium quantity by each fir (either patent holder or licensee) producing variety $i$ as a function of the numbers of firm active in the production of all varieties $\left(k_{1}, k_{2}, \ldots, k_{N}\right)$

$$
x_{i}=\left[1+(1-\mu) k_{i}\right]^{-1}\left[1+\sum_{N} \frac{\mu k_{j}}{1+(1-\mu) k_{j}}\right]^{-1} \text {. }
$$

Replacing expression (A.6) in (1), we can compute the equilibrium price for each variety, and then profit as reported in the text. Furthermore, one can show that $\pi_{k_{i}}^{i}=-2 A^{-4} B^{-3}[A B(1-\mu)+\mu]<0$ and $\pi_{k_{i} k_{i}}^{i}=6 A^{-6} B^{-4}[A B(1-\mu)+\mu]^{2}>0$.

\section{Appendix B. Second-order condition is satisfie at any stable SLE}

We want to show that $V_{k_{i} k_{i}}^{i}<0$. The second-order condition is $V_{k_{i} k_{i}}^{i}=2 \sigma \pi_{k_{i}}^{i}+$ $\left[1+\sigma\left(k_{i}-1\right)\right] \pi_{k_{i} k_{i}}^{i}$. Using the first-orde condition, one can write

$$
V_{k_{i} k_{i}}^{i}=2 \sigma \pi_{k_{i}}^{i}+\frac{F-\sigma \pi^{i}}{\pi_{k}^{i}} \pi_{k_{i} k_{i}}^{i}=2 \sigma \pi_{k_{i}}^{i}+\frac{F-\sigma \pi^{i}}{\pi_{k}^{i}}\left(\pi_{k_{i}}^{i}\right)^{2} \frac{3}{2 \pi^{i}} .
$$

Simplifying further we obtain

$$
V_{k_{i} k_{i}}^{i}=\pi_{k_{i}}^{i}\left[\frac{\sigma}{2}+\frac{3 F}{2 \pi^{i}}\right]<0 .
$$

\section{Appendix C. Proofs of propositions from Section 5}

Denote the symmetric per-fir profi as

$$
V=[1+\sigma(k-1)] \pi-(k-1) F,
$$

where $\pi=\tilde{A}^{-2} \tilde{B}^{-2}=[1+(1-\mu) k+\mu N k]^{-2}$ and $k \equiv k(\mu, N, F, \sigma)$ solves Eq. (3) after having imposed symmetry across all $k_{i}$. 


\section{C.1. Proof of Result 3}

The key of the proof is to show that per-fir profit are decreasing in $N$. Indeed, one can show that

$$
V_{N}=\pi_{N}[1+\sigma(k-1)]+\xi(\cdot) \frac{\mathrm{d} k}{\mathrm{~d} N}<0
$$

where $\xi(\cdot)=\sigma \pi+[1+\sigma(k-1)] \pi_{k}-F<0$ and $\pi_{N}<0$. Hence, as $G$ increases, $N$ decreases and so does $k(\mathrm{~d} k / \mathrm{d} N>0)$.

\section{C.2. Proof of Proposition $1^{\prime}$}

Taking the total differential of (C.1) with respect to $\sigma$ and $N$, one obtains

$$
\frac{\mathrm{d} N}{\mathrm{~d} \sigma}=\frac{\pi(k-1)+\xi(\cdot)(\partial k / \partial \sigma)}{\pi_{N}[1+\sigma(k-1)]+\xi(\cdot)(\partial k / \partial N)},
$$

where $\xi(\cdot)<0$ and $\pi_{N}<0$. Then, the net effect of a higher $\sigma$ on $k$ is given by

$$
\frac{\mathrm{d} k}{\mathrm{~d} \sigma}=\left.\frac{\partial k}{\partial \sigma}\right|_{N}+\frac{\partial k}{\partial N} \frac{\mathrm{d} N}{\mathrm{~d} \sigma} .
$$

Substituting and simplifying one obtains that

$$
\frac{\mathrm{d} k}{\mathrm{~d} \sigma}=\frac{\partial k /\left.\partial \sigma\right|_{N} \pi_{N}[1+\sigma(k-1)]-(\partial k / \partial N)(k-1) \pi}{D}>0,
$$

where

$$
D=\pi_{N}[1+\sigma(k-1)]+\xi(\cdot) \frac{\partial k}{\partial N}<0 .
$$

The proof follows along the same line for $\mathrm{d} k / \mathrm{d} F$ and is omitted to save space.

\section{C.3. Proof of Proposition $3^{\prime}$}

Taking the total differential of (C.1) with respect to $\mu$ and $N$, one obtains

$$
\frac{\mathrm{d} N}{\mathrm{~d} \mu}=\frac{\pi_{\mu}[1+\sigma(k-1)]+\xi(\cdot)(\partial k / \partial \mu)}{\pi_{N}[1+\sigma(k-1)]+\xi(\cdot)(\partial k / \partial N)}<0,
$$

where $\xi(\cdot)<0, \pi_{\mu}<0$ and $\pi_{N}<0$. Then, the net effect of a higher $\mu$ on $k$ is given by

$$
\frac{\mathrm{d} k}{\mathrm{~d} \mu}=\left.\frac{\partial k}{\partial \mu}\right|_{N}+\frac{\partial k}{\partial N} \frac{\mathrm{d} N}{\mathrm{~d} \mu} .
$$

Substituting and simplifying one obtains that

$$
\frac{\mathrm{d} k}{\mathrm{~d} \mu}=\frac{[1+\sigma(k-1)]\left(\partial k /\left.\partial \mu\right|_{N} \pi_{N}-(\partial k / \partial N) \pi_{\mu}\right)}{D},
$$


where

$$
D=\pi_{N}[1+\sigma(k-1)]+\xi(\cdot) \frac{\partial k}{\partial N}<0 .
$$

Hence,

$$
\operatorname{sign}\left(\frac{\mathrm{d} k}{\mathrm{~d} \mu}\right)=\operatorname{sign}\left(1-\frac{(\partial k / \partial N) \pi_{\mu}}{\partial k /\left.\partial \mu\right|_{N} \pi_{N}}\right),
$$

which after some substitutions is equal to the sign of $1-\left(V_{k N} \pi_{\mu} / V_{k \mu} \pi_{N}\right)$. Finally, we show that $\left(V_{k N} \pi_{\mu} / V_{k \mu} \pi_{N}\right)<1$, so that $\mathrm{d} k / \mathrm{d} \mu>0$. Notice that

$$
\frac{V_{k N} \pi_{\mu}}{V_{k \mu} \pi_{N}}<1 \Leftrightarrow V_{k N} \pi_{\mu}>V_{k \mu} \pi_{N} \Leftrightarrow \pi_{k \mu} \pi_{N}<\pi_{k N} \pi_{\mu} .
$$

Some additional algebra shows that $\pi_{k \mu} \pi_{N}-\pi_{k N} \pi_{\mu}=-4 k^{2}(N-1) \mu^{2} \tilde{A}^{-8} \tilde{B}^{-6}<0$.

\section{Appendix D. Comparative statics at the stable SLE}

Consider a stable symmetric equilibrium. Stability requires that the matrix with the typical element

$$
\frac{\partial V_{k_{i}}^{i}}{\partial k_{j}} \equiv V_{k_{i} k_{j}}^{i}\left(k_{i}=k_{-i}=k, \mu, N, F, \sigma\right),
$$

has eigenvalues with negative real parts (Dixit, 1986). Since we are evaluating this expression at a symmetric equilibrium, where $V_{k_{i} k_{j}}^{i}=V_{k_{j} k_{i}}^{j} \forall i, j$, stability implies that $\sum_{j}^{N}\left(\partial V_{k_{i}}^{i} / \partial k_{j}\right)<0$. Following Dixit (1986), a set of sufficien conditions for stability is $\sum_{j}^{N}\left(\partial V_{k_{i}}^{i} / \partial k_{j}\right)<0$ and $V_{k_{i} k_{j}}^{i}\left(k_{i}=k_{-i}=k, \mu, N, F, \sigma\right)>0, \forall i \neq j$. We were able to prove that the latter inequality holds for small values of $N$.

Now, we show that the comparative statics depend only on the sign of the cross-partial. As an illustration, consider the comparative static with respect to $\sigma$. Let $V_{k}=V_{k_{i}}^{i}\left(k_{i}=\right.$ $\left.k_{-i}=k, F, \sigma, N, \mu\right)=0$ defin a stable SLE. The focus on symmetric equilibria implies that one can examine a representative firm Hence, we can write the following:

$$
\mathrm{d} V_{k_{i}}^{i}=\sum_{j}^{N} \frac{\partial V_{k_{i}}^{i}}{\partial k_{j}} \mathrm{~d} k+\frac{\partial V_{k_{i}}^{i}}{\partial \sigma} \mathrm{d} \sigma=0
$$

so that

$$
\frac{\partial k}{\partial \sigma}=\left[\frac{\partial V_{k} / \partial \sigma}{-\sum_{j}^{N} \partial V_{k_{i}}^{i} / \partial k_{j}}\right]=\frac{V_{k \sigma}}{-\sum_{j}^{N} \partial V_{k_{i}}^{i} / \partial k_{j}} .
$$

Since at any stable SLE $\sum_{j}^{N}\left(\partial V_{k_{i}}^{i} / \partial k_{j}\right)<0$, the sign of the expression depends only on the sign of the numerator, which is the cross-partial. 


\section{References}

Anand, B.N., Khanna, T., 2000. The structure of licensing contracts. Journal of Industrial Economics 48, $103-135$.

Arora, A., 1995. Licensing tacit knowledge: intellectual property rights and the market for know-how. Economics of Innovation and New Technology 4, 41-59.

Arora, A., 1997. Patent, licensing and market structure in the chemical industry. Research Policy 26, 391-403.

Arora, A., Fosfuri, A., 1999. Licensing the Market for Technology. CEPR Discussion Paper \#2282. London, UK. Downloadable at http://www.cepr.org/pubs/new-dps/dplist.asp?dpno=2284.

Arora, A., Fosfuri, A., 2000. The market for technology in the chemical industry: causes and consequences. Revue D'Économie Industrielle 92, 317-334 (special issue).

Baye, M.R., Crocker, M.J., Ju, J., 1996. Divisionalization, franchising, and divesture incentives in oligopoly. American Economic Review 86, 223-236.

Bonanno, G., Vickers, J., 1988. Vertical separation. Journal of Industrial Economics 36, 257-265.

Caves, R., Crookel, H., Killing, J.P., 1983. The imperfect market for technology licensing. Oxford Bulletin of Economics and Statistics 54, 249-267.

Corchon, L.C., 1991. Oligopolistic competition among groups. Economic Letters 36, 1-3.

Degnan, S.A., 1998. The licensing payoff from U.S. R\&D. Journal of the Licensing Executives Society International 33, 1-8.

Dixit, A., 1986. Comparative statics for oligopoly. International Economic Review 27, 107-122.

Gallini, N.T., 1984. Deterrence through market sharing: a strategic incentive for licensing. American Economic Review 74, 931-941.

Gallini, N.T., 1992. Patent policy and costly imitation. RAND Journal of Economics 23, 52-63.

Gallini, N.T., Wright, B.D., 1990. Technology transfer under asymmetric information. RAND Journal of Economics 21, 147-160.

Grindley, P., Nickerson, J., 1996. Licensing and business strategy in the chemicals industry. In: Parr, R., Sullivan, P. (Eds.), Technology Licensing: Corporate Strategies for Maximizing Value. Wiley, New York, pp. $345-378$.

Grindley, P.C., Teece, D.J., 1997. Licensing and cross-licensing in semiconductors and electronics. California Management Review 39, 8-41.

Hadfield G.K., 1991. Credible spatial preemption through franchising. RAND Journal of Economics 22, 531-543.

Kamien, M., Tauman, Y., 1986. Fees versus royalties and the private value of a patent. Quarterly Journal of Economics 101, 471-491.

Katz, M., Shapiro, C., 1985. On the licensing of innovations. RAND Journal of Economics 16, 504-520.

Katz, M., Shapiro, C., 1986. How to license intangible property. Quarterly Journal of Economics 101, 567-589.

Rivette, K.G, Kline, D., 1999. Rembrandt in the Attic: Unlocking the Hidden Value of Patents. Harvard Business School Press, Cambridge, MA.

Rockett, K., 1990a. The quality of licensed technology. International Journal of Industrial Organization 8, $559-574$.

Rockett, K., 1990b. Choosing the competition and patent licensing. RAND Journal of Economics 21, 161-171.

Schwartz, M., Thompson, E., 1986. Divisionalization and entry deterrence. Quarterly Journal of Economics 101, 307-321.

Shepard, A., 1987. Licensing to enhance demand for new technology. RAND Journal of Economics 18, 360-368.

Singh, N., Vives, X., 1984. Price and quantity competition in a differentiated duopoly. RAND Journal of Economics $15,546-555$

Taylor, C.A., Silberston, Z.A., 1973. The economic impact of the patent system: a study of the British experience. DAE Monograph 23. University of Cambridge, Cambridge.

Teece, D.J., 1977. Technology transfer by multinational firms the resource cost of transferring technological know-how. The Economic Journal 87, 242-261.

Teece, D.J., 1986. Profitin from technological innovation: implications for integration, collaboration, licensing and public policy. Research Policy 15, 285-305.

Tirole, J., 1988. The Theory of Industrial Organization. MIT Press, Cambridge, MA.

Vickers, J., 1985. Delegation and the theory of the firm Economic Journal Supplement 95, 138-147. 